\title{
Alcohol and the process of economic development: Contributions from ethnographic research
}

\author{
Laura A. Schmidt' and Robin Room ${ }^{2-4}$ \\ 1 Philip R. Lee Institute for Health Policy Studies and Department of Anthropology, History and Social Medicine, \\ School of Medicine, University of California, San Francisco, U.S.A. \\ 2 School of Population Health, University of Melbourne, Australia \\ 3 AER Centre for Alcohol Policy Research, Turning Point Alcohol \& Drug Centre, Fitzroy, Victoria, Australia \\ ${ }_{4}$ Centre for Social Research on Alcohol \& Drugs, Stockholm University, Sweden
}

\begin{abstract}
Drawing on 33 ethnographic studies of drinking in low- and middle-income countries around the world, this paper describes common themes pertaining to economic development, alcohol consumption and related harms. Three crosscutting themes emerged that shed light on why alcohol consumption and problems tend to increase during periods of economic development. First, from the perspective of the global alcohol industry, developing countries often become viewed as emerging consumer markets. Commercially produced alcohol tends to gain a higher status than traditional locally produced beverages, replacing them as resources allow. Drinking and beverage choices thus both symbolize new social divisions and help create them. Second, economic relations change whereby women's interests often lose ground as men's drinking increases. Commercialization of production may mean that women lose control over what was traditionally a home-produced supply. Resources that once stayed in the family or community may be exported as commercial profits. Third, alcohol often becomes both a source and symbol of political tensions and class divisions. Governments may become dependent on commercial alcohol revenues and willing to tolerate high levels of alcohol-related harm. In response, social and cultural movements, often promulgated by women, spontaneously emerge from within developing societies to counterbalance elite interests in the alcohol trade and push against external market forces.
\end{abstract}

The relationships among alcohol consumption, the health of populations and economic development are gaining greater currency in international discussions of public health. Emerging evidence shows that today, non-communicable diseases (NCDs), such as heart disease and cancer, are more prevalent than infectious diseases in low- and middle-income countries (Narayan, Ali, \& Koplan, 2010). Along with tobacco and unhealthy diet, alcohol is one of the key controllable risk factors in NCDs (Room, Rehm, \& Parry, 20II). A recent high-level meeting of the United Nations on the global spread of NCDs has increased attention on how alcohol and other risk factors are affecting the health of developing nations (United Nations General Assembly, 20II).

As part of our service to the World Health Organization's Commission on the Social Determinants of Health, we considered these issues in a review of the worldwide epidemiological evidence on alcohol and inequality, with substantial attention to developing or low-/middle-income societies (Schmidt, Mäkelä, Rehm, \& Room, 20Iо). This

Correspondence: Dr. Laura A. Schmidt, 3333 California Street, Suite 265, San Francisco, CA 94II8, U.S.A.

E-mail: Laura.Schmidt@ucsf.edu

Acknowledgments: This work was conducted under the auspices of the World Health Organization's Commission on the Social Determinants of Health, Priority Public Health Conditions Knowledge Network. We acknowledge the contributions of Pia Mäkelä, Jürgen Rehm and Dag Rekve to the collective work from which this paper has developed. The authors are grateful to the Alcohol Research Group Library for making its holdings and indexing of alcohol ethnographies available for this review. This paper was presented at the Thematic Meeting on Alcohol Epidemiology and Policy of the Kettil Bruun Society at Makerere University, Kampala, Uganda, November I5-18, 2 oro. 
work, focusing on the quantitative epidemiological evidence, showed that alcohol plays an important, but complex, role in the health of developing societies. That said, we observed a general tendency across societies for economic development to coincide with increases in alcohol consumption and related harms at the population level. Rising affluence has many positive impacts on health, for example through improved sanitation and education. In addition, it increases disposable income, and people often use that wealth to consume more alcohol, leading to increased rates of alcoholrelated harm. We also observed that the negative impacts of alcohol tend to result in disproportionate harms for the poorest of poor-those at the lower end of emerging class hierarchies within low- and middle-income countries. People in poorer societies, but particularly the more socially marginalized within those societies, are more likely to drink to intoxication on any given drinking occasion, and tend to suffer more health and social effects from drinking than their more affluent counterparts.

Therefore, while economic development may have many positive impacts on the health of populations, our previous review of the epidemiological evidence on alcohol revealed a somewhat darker side of the story. It also revealed some of the limits of our current understanding of alcohol and development based on the quantitative evidence: while that evidence can describe changes in alcohol-related indicators over time, and can allow one to compare differences between more and less developed countries, it does not shed much light on the mechanisms and processes by which development leads to increases in alcohol consumption and problems.

This motivated us to balance our quantitative review with the present examination of qualitative studies on developing societies. We reviewed selected ethnographic studies on alcohol in lowand middle-income developing societies conducted since the mid-2oth century, with an interest in extracting common themes that were missed by our quantitative review. Virtually all the studies located focused on a single society and most were confined to a single locality within that society. But taken together, they pointed to several key insights into alcohol's role in economic development that were largely missed by our review of the epidemiological evidence.

\section{Background: The quantitative picture}

In our prior work on the social determinants of alcohol problems, we were tasked with assessing health inequalities related to alcohol, by which was meant differences in rates of illness and mortality between different populations and subpopulations, both between and within countries (see Blas \& Sivisankara Kurup, 20IO). Looking between countries, the main emphasis was on comparing richer and poorer countries using quantitative data from disease surveillance systems and multi-site surveys. The differences between rich and poor have also been a major focus of studies within countries, although some researchers have focused on other social differentiations, such as social marginality and gender (Braveman \& Gruskin, 2003; Kawachi, Kennedy, \& Wilkinson, I999).

We observed that alcohol plays two roles in health inequality. The first part of the burden is from alcohol-specific diseases, which are wholly attributable to alcohol in global accounting of risk factors in the burden of disease. Alcohol dependence and other alcohol use disorders count as diseases in their own right, as do several others specific to alcohol in the International Classification of Diseases, such as alcoholic psychoses and alcoholic gastritis. Second, alcohol is a risk factor for a wide variety of disease categories and other harms that are not specific to alcohol, including heart disease, metabolic dysfunction and some cancers (Room, Babor, \& Rehm, 2005). In assessments of the relative contribution of different risk factors in recent years, alcohol has ranked no lower than fourth in global accounting for the burden of disease (Ezzati et al., 2002).

The quantitative evidence suggests that abstinence rates tend to be higher in developing societies, particularly in very poor societies, and that percapita alcohol consumption is generally higher in richer than in poorer societies. Alcohol is responsible for a much larger fraction of the burden of disease in richer than in poorer societies. This reflects not only the higher volume of drinking in richer societies, but also the smaller set of important competing risk factors that predispose people to poor health. It seems likely that rates of disease and problems per liter of pure alcohol are generally higher in poor countries, but this is not well measured.

In terms of other social differentiations, in most places men tend to be more likely than women to drink, and to drink more than women. But there are great variations in the extent that 
men's and women's drinking differs by degree of affluence, both within and between countries at different stages of development. In general, levels of drinking by men and women are closer together in more affluent groups within a given society, and in richer societies compared to poorer ones. Patterns by age among adults appear to vary considerably between societies, so that no generalization on this can be made.

Prospective data, where available, also point to the adverse effects of development on alcohol consumption and problems. Alcohol consumption levels have often risen in the process of economic development, particularly as people move out of extreme poverty and destitution. However, there continues to be a greater burden of ill health and other harm for a given level of drinking in the poorest segments of a given population, and levels of harm are often observed to rise steeply in early stages of economic development.

\section{Limits of the quantitative evidence}

What has been stated so far can be learned from quantitative research fairly universally, since such data, in the form of population surveys and cause-of-death statistics, are increasingly available for poorer countries as well as wealthier ones. However, epidemiological research has several inherent limitations. A crucial one is that the preponderance of the alcohol produced and consumed in most developing societies is unrecorded by official statistics, either because it is brewed in the home, traded for in-kind goods and services, or illegally distributed. Consequently, epidemiologists are dependent on self-report population surveys to systematically measure and quantify alcohol consumption. Sales and tax records in these societies are grossly incomplete, and survey-based reports are frequently limited to particular regions and subject to reporting bias. By contrast, in more affluent societies, it is possible to go considerably further on the basis of quantitative data. Here, survey data are more abundant, and sales records more accurate and comprehensive as to what is actually produced and consumed.

The existing quantitative literature is also generally much less helpful on issues of change over time, and the interplay of alcohol and processes of economic development. This is a problem of costs and logistics. It is costly and challenging to conduct population-based surveys in developing societies given the need to cover large rural areas, much less to do them repeatedly over time.

A final limitation results from the fact that the epidemiological literature is, by design, positiv- ist in orientation. Scientists attempt to derive "just the facts" and purge from the data issues of social evaluation and morality. But alcoholic beverages have a dual nature. On the one hand, they are physical commodities with effects on the body and mind when ingested, as well as having interactions with other substances, environmental and personal factors. On the other hand, alcoholic beverages are cultural artifacts and their use is highly charged with symbolism. To use the word "champagne" carries strong connotations of celebration and luxury in Westernized societies, even for people who have never had a sip. At the other end of the spectrum, cultures where drinking is common tend to have a variety of labels for alcoholic beverages that are "demerit commodities," to use the economists" term-in English, such labels as "rotgut," "plonk" and "red-eye" (Room, Mäkelä, Schmidt, \& Rehm, 2006).

The positivist orientation of epidemiology tends to leave the current body of science agnostic on these value-laden, symbolic attributes. However, many of these associations are pertinent to understanding the connections between alcohol and inequality, and in relationships between the developing and developed worlds. Poor people who drink seem to be quite heavily stigmatized across the whole range of societies (Room, Rehm, Trotter, Paglia, \& Üstün, 200I), as one Honduran ethnographic informant described:

"Like if somebody that's poor gets drunk, really drunk, they'll go, 'Oh look, there goes a fucking alcoholic wino, pachanguero,' but if somebody really rich gets drunk they'll go 'Oooh' [in a comical tone]. It'll be like, fun, you know: 'Look at the doctor, he got a little bit drunk.'” (Pine, 2008, p. 95)

Ethnographic studies often provide vivid portrayals of the changing values and moral categories associated with different forms of alcohol over the course of economic development. This can be important for understanding how consumption, problems and incentives to drink change during development, and how the burden of social stigmatization and marginalization may become spread across classes and other social groups.

\section{The basis for this essay}

We confined our coverage of the literature to major ethnographic studies that explicitly focused on alcohol 
in the context of developing societies, and that were published since the mid-2oth century. Many of these studies cannot easily be found through databases of articles or even through search engines. So to locate studies we drew primarily on the holdings of the Alcohol Research Group Library in Emeryville, California, one of the largest collections of alcohol research studies in the world, as well as on personal networks. In total, we reviewed 33 ethnographies from different parts of the world, including India $(N=5)$, Africa (including South Africa) $(N=7)$, South Asia $(N=1)$, Central and South America $(N=6)$, Aboriginal communities in Australia $(N=3)$, Papua New Guinea $(N=2)$, Native American communities in the United States $(N=3)$, and Indonesia, Polynesia and Micronesia $(N=6)$. Our selection of studies privileged those that followed groups and localities for a considerable period of time, yielding invaluable information of the changing dynamics of alcohol and development, and we made sure to cover different world regions. The primary goal was to extract a few common themes that illustrated the new kinds of evidence that existing ethnographic studies could contribute to the quantitative evidence, to the point of analytic saturation.

We focused our search on studies carried out since the mid-2oth century for two reasons. First, these studies are likely to be more relevant to today's discussions around health inequality and economic development because they are relatively contemporary. Second, the pre-I96o tradition of anthropological writing had a tendency to underplay the harms associated with alcohol-partly because of ethnographers' functionalist leanings and partly due to the fact that these, mostly male, anthropologists often lacked access to the groups most aggrieved about drinking, such as women (Room, I984). In the words of Christine Eber, who studied gender and drinking among the native pendranas of a highland Maya town,

Listening to pendranas tell me about problem drinking and then later analyzing what they told me, I came to believe that drinking has probably always been more problematic ... than seems apparent from the ethnohistorical record. Staying only one year in a community and talking mostly to men, anthropologists are not able to get much past normative drinking, which in most societies isn't problematic for most of the population. To learn more about deviations from norms it takes time, and talking with people of all ages and groups. (Eber, I995, p. 8)

\section{Common themes}

We report on common themes that emerged across the 33 ethnographies reviewed for this study. These pertain to: (I) the effects of changing alcohol availability with the emergence of economic development and consumerism, (2) changing economic relations linked to alcohol production and distribution, and (3) political and class tensions around alcohol in the context of development. Changing relationships and tensions between men and women comprised another theme that cut across all three of the above.

\section{Developing societies as consumer markets}

A central theme in many of the studies we reviewed involved how, in an increasingly globalized world, developing societies represent the major remaining untapped markets for corporations in the business of producing and distributing alcohol. The impulse to turn colonies into markets emerged in the Igth century, so by the mid-2oth century, the beginning of the period we are considering, production facilities for western-style alcoholic beverages had been established in many developing countries across the globe (see Jernigan, I997). Many of our ethnographic studies reveal how economic development leads to the emergence of a cash economy in which alcohol takes its place as a commodity, becomes commercialized, and becomes more widely available in new, often more concentrated, forms. Some show in vivid terms how the harm associated with increased alcohol availability is seldom borne evenly across groups within the populations of developing societies. Emerging elite and middle class groups typically have better access to foreign brands of alcohol, which often become symbols of their more modern outlook and cosmopolitan identity (Butler, 2006). Those who are less well off often seek these new forms of alcohol as symbols of social status, sometimes to the detriment of their health and economic well-being (Grossman, I982).

In fieldwork by Martha Macintyre, we find a contemporary microcosm of these dynamics as they are unfolding among Lihirians in the province of New Ireland in Papua New Guinea. In this case, the engine of economic development has been the recent entry of a foreign mining corporation into the island economy. Macintyre's work includes a careful comparative analysis of how the mining industry is 
affecting four different villages on the island. Indepth studies of these villages show a direct correlation between the perceived negative impacts of drinking-adverse effects on family life, sexual offences and deteriorating relations between women and men-and the village's physical proximity to the mine. Her work further documents that alcohol consumption is more common in areas close to the mine because of increased availability-in Macintyre's words, "because there is more money available and because these people have better access to liquor outlets" (Macintyre, 2005). Development has also brought the emergence of a social class hierarchy to New Ireland where there was little social differentiation before. Alcohol use and problems are directly implicated in the island's growing problems with class inequality. In the words of a 35 -year-old Lihirian man:

"At the top now are all the white men who live in the best houses and all drive cars and have a club. . . . Then there are the relocatees [who were paid for their land] who all have big houses and cars and businesses and they have compensation money to spend. Now they are all greedy troublemakers who do not share their money with others, even their own clan and family. They throw away their money and then just ask [the mining corporation] for more. They all drink too much.

Then there are the employees at the mine who have regular wages and can buy things like rice and tinned meat for their families, but they are not very rich. ... They spend too much of their money on beer. . . . These men are ruining the place, making their wives work in the gardens and not giving them money for food and . . . just throwing their money away on drink.

At the bottom are the villagers like us who were promised that Lihirians would all benefit, and now we just watch as all the promises are broken. Here we have no water supply, no money, no road, no cars, no boats. We can no longer afford to buy things at the supermarket. . . That's Lihir now, a few with plenty, the village people, nothing. Before we were equal, now we are at the bottom. That's what the mine has done for us." (Macintyre, I999, p. 46)

Suggested in this account is a self-reinforcing dynamic that is observed in many of the societies studied: emerging elite and middle classes with newfound disposable income form a consumer market for foreign alcohol products. Foreign alcohol products thus emerge as symbols of a better life, thereby increasing their commercial value and further expanding the consumer market. As Elizabeth Colson and Thayer Scudder conclude from their fieldwork in Zambia, "thirst seems to grow as more men and women attain a cash income, and as brewers and distillers expand their operations" (Colson \& Scudder, I988, p. I). Moreover, as foreign drinking practices are introduced and alcohol distributors appeal to new markets, drinking often becomes acceptable in a wider range of groups within the population. While historically, alcohol consumption had been proscribed for women in most of the societies studied, with development often comes the emergence of a new class of educated women who take up drinking as a symbol of gender equality and independence (Benegal, Nayak, Murthy, Chandra, \& Gururaj, 2005).

Across the different societies studied, young adult men often form the group that seems the most ready to embrace new drinking practices introduced from the outside. Christine Toren's contemporary ethnography of villagers on the island of Gau in Fiji describes how consumption of European brands of beer has supplanted traditional kava (a traditional mildly psychoactive, non-alcoholic drink) as the preferred beverage among young men (Toren, I994). As one female informant described the change in drinking and the accompanying public problems,

“Today, all the young men want to be Europeans. They're always going off . . . to drink beer until they're drunk. When they return here they make a lot of unpleasant noise, fight each other and I don't know what else. It looks bad, it is not respectful, they neglect [the reputation of] the village." (Toren, I994, p. I57)

Toren's work highlights how changes in alcohol availability and consumption can give rise to deeper divisions within developing societies. In the case of Gau, western modes of drinking have di- 
vided young people and elders in the community by introducing a set of cultural contradictions that now frame daily life: "inside" versus "outside" the community, kava versus European beer, the "ritualized" versus "haphazard" use of psychoactive substances, and "dignified behavior" versus "rowdiness and fighting."

Colson and Scudder (1988) note similar tensions in Zambia, where villagers in the Gwembe District have come to measure social worth in terms of urban fashions, including a preference for the more "sophisticated" drinking of imported beer in beer halls and bottle shops, rather than in homesteads. The consequences of this cultural shift in the status of alcohol have included across-the-board changes in most aspects of drinking: an increase in the volume of alcohol consumption per occasion, in the frequency of drinking per week, in reasons for drinking and in alcohol-related problems:

The frequency of purely social drinking has ... increased, first among men and more recently among women. So has the amount of drunkenness, with associated violence. ... The changes in behavior can be summed up by saying that drinking among men has increased substantially with respect to both the amount consumed on any one occasion and the frequency of drinking. ... Whereas in the past most drinking was well grounded in either ritual or labour activities, drinking has now become an activity on its owndrinking for drinking's sake. (Colson \& Scudder, I988, p. I5-16)

In most of these ethnographic studies, differentiations and tensions emerged between gender groups around drinking. Poor women often lose by their men's drinking, not only in terms of the man's drunken comportment, but also in terms of the resources available for family life. Butler (2006) describes the scene in the local taverns in rural Ecuador:

The young wives in cantinas gather up their husbands' watches, ponchos, and hats, because these are easily lost or stolen when their husbands are drunk, then sit on the edge of the room and wait. They fear drunken violence between their husbands and other men while in the cantina and violence against themselves when they go home. They try to come between the combatants, as a group, in the cantina and only hope there will be others to defend them when they are home. Helplessly, they watch their household's disposable income sliding down their husbands' throats. (Butler, 2006, p. I83-I84)

A related theme involves economic consequences for the poor who seek increased status by drinking new brands of foreign alcohol. Colson and Scudder (I988), for example, document a growing proportion of wages over time earned by men in the Gwembe District, Zambia, that is diverted from households for the purchase of bottled beer. Similarly, in a study of the socioeconomic impact of drinking in Karnataka, India, a group of ethnographers found that per-capita expenditures on food, health and education were substantially lower in households where men drank, compared to nondrinking households (Thimmaiah \& Sharma, I978).

From reading the reports of these ethnographers, it seems almost inevitable that when foreignproduced alcohol takes on elite status, there will be a concomitant degradation in the status of other, more traditional, forms of alcohol. Abeyansinghe's (2002) study of drinking in Sri Lanka dramatically illustrates the symbolic roles that different forms of alcohol have come to play in defining social groups. In this highly stratified caste society, if and what one drinks has become a central signifier of social status. Middle-class people, such as government workers, traders and taxi drivers, drink the local beverages arrack and toddy, but avoid even coming into contact with the widespread illicit form of alcohol, Kasippu. As the researchers observe, a "class barrier" keeps the middle class from drinking Kasippu, not to mention the fact that this beverage is often adulterated with toxic substances to give it "more kick":

The middle class of Sri Lankan society in particular evince attitudes of ambivalence and bigotry towards alcohol. This is particularly evident in such ideas as the fact that any drinking is bad within the class and any form of excessive and uncontrolled drinking such as of illicit liquor (popularly known as Kasippu) is acceptable 
among the poor. (Abeyansinghe, 2002,

p. I3)

In this highly polarized context, Kasippu drinkers, who are largely poor, slum-dwelling, day laborers, form a marginalized subculture defined by "social stigma and guilt." They are physically and socially "isolated from the rest of drinking culture" by wholly separate modes of alcohol manufacture, transport, distribution, sales and drinking venues. What the ethnographers thus describe are "two drinking worlds [that] seem to have a parallel existence" but seldom intersect-moralized social worlds that justify social exclusion by blaming marginalized groups on the basis of their drinking. Tragically, those who are marginalized often internalize the blame, as Abeyansignhe's interviews of slumdwelling Kasippu drinkers show:

These besotted people who have got trapped into a life long addiction realize this only too well. "This is our [karma]" and "I have only a few years to live" are some of the remarks made by them. (Abeyansinghe, 2002, p. 9I)

Last, we found some tensions and divergences in these ethnographic accounts concerning the reasons why alcohol appears to have such a detrimental impact in many of the developing societies studied. Many of these ethnographers tend to argue that increases in alcohol-related harm are largely driven by the wider availability of alcohol in more concentrated forms. But often implicit in their firsthand accounts is a sense that other forces contribute to the harm caused by alcohol, involving the acute social stresses that come with the involuntary resettlement of communities, political frustrations and the demoralization of men.

Particularly where men have traditionally held great power and authority within their communities, the political and social-structural changes that come with development often bring new, unfamiliar roles that afford less respect and status. Increased drinking among men and alcohol-related violence may be expressions of this demoralization and loss of control. Thus, in Colson and Scudder's account of Zambian society between the I950s and I980s, the combined pressures of guerrilla warfare, a massive population resettlement program and economic decline seemed connected to the rise in drinking among men, and particularly to dramatic increases in alcohol-related violence toward women-expressions of the "numerous insults to [men's] self-esteem" brought about by social change (Colson \& Scudder, I988, p. I6). Silberschmidt describes similar changes in men's drinking in rural Kenya:

Men are faced with a new life situation that many are not able to cope with, and they have not found other ways of acquiring new roles from which they can get a feeling of self-respect and self-reliance .... In their frustrated situation, alcohol seems to be an escape. Besides, when they go to barsmen mostly drink together with other men and not alone-they meet with other men in the same situation as themselves, and they get some social contact. (Silberschmidt, I990)

Pine (2008), however, has a different interpretation of the cultural association of violence and the drinking of the poor in her study of Honduras. This is a society with what she describes as a history of structural and institutionalized violence. In such a context, the culture's linking of violence with the intoxication of poor men becomes a way of individualizing the social interpretation, and diverting attention away from structural and institutional determinants of socioeconomic inequality. Still, Pine acknowledges an objective reality in the link, remarking that "drinking is one way to perform a rebellion against structured oppression," although the "retributive violence that [drunks] are best able to take part in is against those closest to themtheir families, other drunks, and other people from their social milieu" (Pine, 2008, p. 96).

\section{Changing economic relations linked to alcohol production and distribution}

A second theme in the ethnographies we reviewed involves how alcohol can exacerbate economic inequality and contribute to impoverishment. In the emerging cash economies of the developing world, the production and sale of alcohol represent a substantial potential source of revenue. Depending on how the production and distribution of this commodity unfolds locally, it can have significant impacts on the population. Some of our ethnographers were able to see up close, and document, economic mechanisms at the local level that link alcohol with growing inequality. In some of the studies reviewed, changes in alcohol production and distribution resulted in the impoverish- 
ment of particular groups within the community, such as women. In others, it led to more widespread community impoverishment following the corruption of local officials or their neglect of community need.

In many of the societies studied, it was traditionally the business of women to produce indigenous forms of alcohol for bartering, work parties and ceremonial uses. With development, it was observed that outsiders often colonized the production and sale of alcohol, thus upsetting traditional economic and gender relations within the society. Multinational firms, often in partnership with local entrepreneurs or politicians, might gradually take over a larger share of the market for alcohol, often in the form of heavily promoted western-style lager beer (see Jernigan, I997). While this dynamic is found in many societies (e.g., Eber, I995; Maula, I997), one of the most detailed accounts is provided in Colson and Scudder's (I988) study of the Gwembe District in Zambia, which went through important changes in alcohol distribution channels and drinking practices during the lengthy study, conducted between the I950s and the I980s.

Prior to I950, local women in the Gwembe District produced only small amounts of lowpotency traditional beer for the purposes of rituals and work parties. Beer-brewing technology was simple, intensive labor was required and the beer would not remain potable for long, which meant that it was rare to produce beer in excess of what was immediately needed. Due to limited means of storage and transport, little alcohol traveled far from the point of production, and all that was made was typically consumed quickly.

After I950, with the development of local fishing and mining industries, and the emergence of a cash economy, beer brewing increasingly became a commercial industry. By the I96os and I970s, domestic brewing became a major source of village income for the women who served as brewers. Metal drums were now available for women to brew larger quantities of beer in return for cash payments from men. Over time, however, local women brewers faced new competition from politically connected men who opened beer halls and taverns to sell commercially produced beer, trucked in from the capital city on the new roads. Initially, home brews were sold for about half the price of commercially produced ones, thus allowing women brewers to remain competitive.

Colson and Scudder report that by the I980s, urban breweries and numerous local bottle shops had rendered the women brewers unable to compete. They further document the significant adverse consequences that this had for the local economy. As local women lost the beer franchise, they lost their primary source of independent income. According to Colson and Scudder's accounting of household expenditures, profits from beer sales had been critical to sustaining life in the village: overall, one-fourth of profits from homebrewed beer sales went to purchasing food for families, whereas $21 \%$ went to transportation and $\mathrm{I} 6 \%$ to clothing (Colson \& Scudder, I988, p. 93). Women's beer profits not only supported day-to-day survival throughout Africa, but also helped create the possibility of upward mobility for young people. Thus in a study of young college-bound woman at the University of Dar es Salaam, one woman noted, "I would not stand here had it not been for my mother's brewing" (Beckman, I988, p. 39).

Colson and Scudder further describe how the shift in beer production had adverse consequences for the distribution of wealth in the community. In the I950s, women's production and distribution of beer had helped redistribute wealth between the sexes, thereby empowering women. When men used wages earned in the local mines and fisheries to purchase home-brewed beer from local women, they not only helped to redistribute income from men to women, but they also kept wealth circulating through the local economy. To the extent that men spent increasingly large proportions of their cash earnings on alcohol in private and government-owned taverns, wealth migrated outside the village. Colson and Scudder's case study shows how African women lost doubly when they lost the beer brewing franchise-they lost both in terms of the market moving away from them, and in terms of their own empowerment vis à vis menincluding their ability to control the level of the men's drinking by their control of the supply.

In addition to such changes in gender relations, the ethnographies we analyzed described more general changes in economic relations between the populations and their local governments. In many of the societies studied, development and commercialization led local governments to become more dependent upon the excise taxes, tariffs, licensing fees and profits generated from sales of alcohol. Where governments became dependent on these revenue streams, they commonly faced the challenge of negotiating two competing interests. For revenue purposes, government officials developed an interest in maintaining high levels of alcohol consumption in the community. Yet, in their 
roles of protectors of the public health, these same officials had an interest in reducing consumption to control alcohol-related harm (see Mäkelä \& Viikari, I977). Growing harm and health inequality was a consequence when government officials privileged the former over the latter interest.

The just-discussed study of Zambia's changing beer industry was one such case. Even as rising alcohol consumption and problems became a significant source of public disturbance in the Gwembe District, Colson and Scudder describe a municipal government that did little to establish formal controls on the distribution of alcohol. This was attributable to the fact that "the main producers of alcoholic beverages [were] parastatal enterprises, and the income from licensing and the profits of their own taverns [was] a major source of income for municipal and rural councils" (Colson \& Scudder, I988, p. I9). The irony of this situation was not lost on the local people:

The government, despite its occasional pronouncements encouraging sobriety, profited from its involvement in the liquor trade, a fact well recognized by rural people as they listened to visiting officials address local gatherings on the evils of excessive drinking. (Colson \& Scudder, I988, p. 58)

In a very different part of the world, two ethnographers report similar tensions for local government officials invested in the alcohol trade. Throughout the I970s, I980s and I990s, Mac and Leslie Marshall made repeated returns to the town of Moen in Chuuk, Federated States of Micronesia. As elsewhere in Micronesia, Moen had no indigenous drinking tradition. The introduction of alcohol by whalers and traders in the late Igth century was sudden and rapid, and concentrated forms of alcohol conspired with cultural patterns to produce a considerable degree of violence, explosive drinking and public disorder (Marshall \& Marshall, I975, I976). Moen was also a place where the municipal government became deeply dependent upon revenues from alcohol taxation, licensing and a government-run alcohol monopoly, as well as being invested in building a market for tourism, with alcohol viewed as a necessary commodity for attracting foreigners.

The Marshalls observed that, over time, the volatility of drinking in Moen became a pronounced source of public disruption, as evidenced by remarkably high rates of alcohol-related violence against women, traffic crashes, homicides and injuries (Marshall \& Marshall, I990). The problems appear to have peaked in the late I970s, when drunken gangs of Moen men began threatening an all-out "war" with drinking gangs from a neighboring island. Even this extreme degree of public disruption, however, seemed to be tolerated by local officials. Change only became possible when local women organized a popular movement for prohibition and persisted with their organized resistance over several years. Moen is one case where alcohol prohibition appears to have successfully reduced problems in the community, at least in the Marshalls' assessment. Under prohibition, Moen came to tolerate a vigorous black market in alcohol production and speakeasies, generating income for local elites. However, because drinking was officially illegal, most drinking is clandestine and thus disturbances occur in settings where others would be able to intervene before someone was seriously hurt (Marshall \& Marshall, I990).

The case of Moen shows that, while governments dependent on alcohol revenues may be willing to tolerate high levels of alcohol-related harm, local communities may not. Jarratt and Zwar (1989) describe a similar situation among Aboriginal Australians, but one in which events unfolded somewhat differently. In the late I980s, elders in Queensland's Aboriginal communities began to push for the reintroduction of old paternalistic laws controlling alcohol. Paradoxically, the plea came when revenue from the profits of alcohol sales were relieving heavy financial burdens on the local government, as well as underwriting the development of needed community services and public works. The issues at stake were complex. On the one hand, Jarratt and Zwar interviewed local health clinic directors who argued that "access to these canteens-and sly grog [illegal alcohol] brought into the communities[was] simply allowing Aborigines to destroy themselves." On the other hand, spokespeople for public affairs argued that the elders' plan for prohibition would lead to a "really bad situation, [since] it would be highly desirable that people drink as much as possible so they could have plenty of money to do public works [in the communities]. And we all regret and lament that this is the case." Likewise, McKnight (2002) documented, on the one hand, the devastation associated with drinking in the Aboriginal community on Mornington Island in northwest Queensland and, on the other hand, the dependence of the local government on revenue from alcohol sales in the community canteen. In such circumstances, there were moves in many Aboriginal communities in 
Australia to impose restrictions on alcohol availability (e.g., Wright, I997).

The changes in alcohol distribution described in the ethnographies are part of more general processes of economic development, applicable also to other items of mass consumption. But alcohol is a special commodity both in its potential harm to health and its dependence-producing properties. Concentration of alcohol production into a smaller number of enterprises can allow governments in developing countries to exercise more control over the market and to raise taxes. Higher alcohol taxes, by suppressing consumption, can contribute to public health as well as to government revenues. However, to the extent the new producers and distributors succeed at "growing the market" with advertising and other promotion, rates of alcohol problems will very likely rise. And the new methods of production and distribution of alcoholic beverages usually contribute to increased consumption, since more alcohol, and more concentrated forms of it, can be made available. These trends, as suggested by the Zambian case, may have particularly adverse effects on the social situation of women.

\section{Alcohol as source and symbol of political tensions and conflict}

The ethnographies we reviewed underscore alcohol's dual nature in the context of development: it comes to serve as both a source and symbol of inequality. As a consumer product, alcohol is linked to wealth for those who control its production and distribution. As a status symbol, specific brands and patterns of alcohol consumption help societies sort the poor from the affluent, and the marginalized from the mainstream. Given this, it should come as little surprise that a number of the ethnographies reviewed described the eruption of political conflicts surrounding alcohol. Some of these movements to prohibit drinking (especially by the poor) came "from above," as in cases where foreigners and elite groups used alcohol prohibition to control indigenous populations or to create a sober workforce of wage laborers. Other social movements around alcohol, however, emerged "from below," as indigenous groups came to see the use of alcohol as a tool of elite domination - as a symbol of the elite's ability to quell political uprising by "anesthetizing" the population (Fahey \& Manian, 2005; La Hausse, I988). In some of the societies represented, the political history was punctuated by the repeated back-and-forth of pro- hibition movements coming from both directions, as in communities throughout Micronesia:

Throughout Oceania, prohibition was one of the first laws colonial governments enacted. With independence movements leading to self-government following World War II, deprohibition-ushering in the "right to drink" - was a common change, often made even before the end of colonial rule. Given this background and the symbolic value of drinking as a sign of equality, it is surprising and somewhat ironic to discover recent instances where islanders themselves have reimposed prohibition. (Marshall \& Marshall, I990, p. 7)

South Africa has a long history of colonial domination involving alcohol that, as observed by contemporary ethnographers (e.g., La Hausse, I988), has had a significant societal impact. Especially in the wine-producing regions of South Africa, colonials used alcohol as payment for African labor over generations, largely because it reduced labor costs and allowed farmers to extract more effort from workers. In the 300-year-old wine farming industry on the Western Cape, the "tot system" provided laborers with regular wine rations throughout the day. The tot system had significant benefits for farm owners: wine rations were taken directly out of cash wages, thereby reducing labor costs, especially since the wine given to workers tended to be poor quality. Moreover, as workers became increasingly dependent on drink, they were less inclined to leave the employer; the promise of daily rations appeared to have made workers more willingly accept harsh conditions.

With the growth of cities in the first half of the 2oth century, efforts to control South African drinking took the form of government-owned beer hallsknown by Africans as "drinking in the cage." The first municipal beer hall was established in Durban, and the sale of beer to Africans became the primary source of revenue for funding local police and prison-like barracks to house workers. When it became apparent that home-brewed beer produced by local women undercut the rationing system, and also competed with beer hall sales, the Durban town council established licensing laws and began police raids on women brewers, along with their aggressive prosecution in the courts. 
In the I930s and I940s, resentment toward the beer hall system erupted in an organized boycott sponsored by the black workers' labor union. The results of the beer hall boycott were profound for white authorities, with municipal budgets sustaining heavy financial losses. Eventually, the authorities softened their stance on alcohol controls. But beer halls again became the stage for political action in the late I950s and the I960s, this time by the Women's League of the African National Congress (ANC), which sought to defend South African women's ownership of the homebrewing industry. In I959, ANC women attacked Durban beer halls with sticks, fought with police, and ultimately set one beer hall on fire. As one activist explained, "'Our real grievance over the beer halls was that the home-brewing of this traditional drink of the people is not allowed, [while] the Corporation [local government] turns it into a revenue-making commodity”' (La Hausse, I988, p. 63). As the ANC leader, Albert Luthuli, later reiterated, “The beer hall has become for us a symbol of legal robbery by whites"' (La Hausse, ı988, p. I).

Other movements for alcohol control "from above" occurred in many other parts of the developing world throughout the late igth and early 2oth century, reflecting the efforts of missionaries and temperance workers in European colonial empires to reform both imperial practices and the subject populations. Thus the first international treaty to control a psychoactive substance was the agreement between the colonial powers in 1899 to ban sales of "trade spirits" to indigenous Africans in most of Africa (Room, 2008). From a mixture of motives, in the course of the Igth century the settler societies in Australia, New Zealand, Canada and the United States prohibited the sale of alcohol to the indigenous populations. A more recent manifestation of such an impulse was the Australian federal "intervention" in the Northern Territory in 2007, which included new restrictions on alcohol sales in remote indigenous communities (Australian Indigenous Doctors' Association \& Centre for Health Equity Training, Research and Evaluation, 20I0).

In terms of grassroots movements, several of the ethnographies reviewed describe popular movements for alcohol prohibition "from below" (e.g., Marshall \& Marshall, I990). In such cases, alcohol often serves a symbolic function by defining the clash between classes and status groups, as well as the need for a sober populace that can fight for greater equality and defend tradition. In the context of India's struggle for independence, Mohandas Gandhi pressed for the inclusion of alcohol prohibition as a plank in the Congress Party platform on the grounds that a sober population would be better able to govern itself (Dorschner, I983). In revolutionary Chile of the I970s, prior to the military coup, the "alcohol problem" became viewed as a "political problem" tied to its tendency to inhibit social and political participation (Weinstein, 1976). Here, excessive drinking became defined as a force that alienated workers from the historical task of perceiving and analyzing their social situation, and joining in action to change the society:

We stand before an ideological struggle, on the threshold of the development of a new culture, expressed in changes in power relations. Workers are becoming the country's leading class. In order to reach that aim they must realize all their potential. Excessive social or addictive use of alcohol limits productivity, the possibilities for ideological advance, the attainment of power, and the capacity to incorporate women in the process of social change. This concept can be summarized with the help of a slogan that begins to be heard in some working class communities: "Alcoholism is opposed to the revolutionary process.” (Weinstein, I976, p. 76)

Within these political conflicts, drinking practices often come to serve as symbols of tensions that arise when indigenous societies confront the radically different cultures of outsiders. Christine Eber (1995) presents a fascinating case in which alcohol came to take on multiple meanings among highland villagers in Chiapas, Mexico. These meanings reflect underlying political tensions around changing gender roles, the encounter with evangelical Protestantism, and the ongoing revolt against the national government, all which became symbolized in choices about drinking. Eber observes that women in the mountains of Chiapas continue to this day to sell native chicha, a fermented sugar cane drink, out of their homes. However, use of rum or aguardiente-translated as "burning water"-also has a long, albeit ambivalent, place in the cultural order of the native pedranos. On the one hand, rum has been integrated into religious rituals as "holy water." In Eber's analysis, this has served as a way of symbolically negotiating the dangerous and powerful presence of European outsiders in their homeland. But rum still remains a symbol of the historic encounter with Europeans in the I500s, when it 
served as "a tool of domination"-for many pedranos, rum is believed to be a Satanic influence (Eber, I995, p. 32).

These cultural contradictions in Chiapas came to a political head in 1946 , when government officials established a monopoly on the lucrative rum trade. Local pedranos responded with organized resistance, including a boycott of the town market and violence that led to a series of murders of purported informants or "witches." The "Rum War" was resolved in I954 when representatives of the indigenous community argued in defense of access to rum on religious grounds-as "holy water." This story continues to unfold in the context of current battles over independence in Chiapas. For many in the Chiapas villages, Eber (200I) reports, alcohol and its attendant problems have come to be seen as a core issue, and as a symbol of political and economic domination, resulting in calls for local prohibition.

Butler's (2006) ethnography of poor Otavalan (Quichua-speaking) communities in Ecuador emphasizes the power struggle with mestizos, Spanish speakers who ran the cantinas in the towns and controlled the local supply of spirits. The cantinas in town were seen by the Otavalan women as a kind of trap where unlimited alcohol supply and unlimited credit would keep men and even some, usually older, women drinking beyond their physical, emotional and financial capacity (Butler, 2006).

Over the years, three separate groups of outsiders argued to whoever would listen in the Otavalan communities that a social change was needed to steer the community away from a situation of growing "drunken dissipation"-groups including evangelical Protestants; Catequistas, from the Latin American liberation-theology movement among Catholics; and sympathetic government functionaries. Little changed until there was a devastating earthquake in I987. This was taken as a sign from God that change was needed, and Butler describes in some detail the sobering of the community and its cultural rituals that followed. Women today in the community, she writes,

have a greater expectation that they can form productive relationships with their husbands. . . . It is with a visible relief that women report and promulgate the new views about drinking. For Catholics, a few binges are manageable, even pleasurable, if kept relatively short-lived, but the vast majority of money coming into the family will now be used for education, food, clothing, and small household appliances. . . . For Protestants, the hope is that alcohol will not take one dime away from these household expenses. (Butler, 2006, p. 388)

\section{Discussion}

We reviewed 33 ethnographic studies on alcohol in developing societies, covering a diversity of societies from different regions of the world. Despite such wide variation, their accounts of alcohol and development shared some important commonalities. Three common themes involved the harms that accompany the commercialization of alcohol in developing countries, changing economic relations around alcohol production and distribution, and alcohol as an issue and arena for political conflict. Across studies, we observed a similar sequencing and generic process that helps account for why alcohol consumption and alcoholattributable harm tend to increase during the course of economic development. Through this process, economic inequality between countries (i.e., between more and less developed countries) appears to beget economic and health inequality within countries. Growing inequality within developing countries often appears to occur across gender lines, and between emerging elite, middle and lower classes.

The general progression seems to start with the commodification of alcohol as societies enter the global economy and become "emerging markets" to outside commercial producers. Commodification increases the availability, consumption and, therefore, the harmful consequences of drinking within the population. The burden of harm, however, is seldom borne evenly across groups within the population. Emerging elite and middle-class groups typically have better access to foreign brands of alcohol, which become symbols of their status and more cosmopolitan identity-as one informant in Toren's (I994) study of Fiji put it, “'Today, all the young men want to be Europeans.'” Those who are less well off may seek these new forms of alcohol as symbols of social status, but often to the detriment of their own health and economic standing. Finally, those marginalized at the very bottom of the emerging class structure tend to drink highly stigmatized local products. In Sri Lanka, for example, the act of drinking Kasippu signifies that one is poor, a slumdweller and to blame for one's personal misfortune. 
Commodification also means that the symbolic nature of alcohol takes on a life of its own. Drinking and beverage choices, therefore, both symbolize new social divisions and help to create them. Governments may become dependent on commercial alcohol revenues and willing to tolerate high levels of alcohol-related harm. In response, social and cultural movements, often promulgated by women, emerge spontaneously from within developing societies to counterbalance elite interests in the alcohol trade and to push against external market forces. Studies in Chiapas, South Africa, Fiji, Papua New Guinea, India and native communities of Ecuador underscored the importance of resistance tactics and indigenous political resources in mitigating the adverse effects of alcohol on population health. In all cases, political struggles captured the dual nature of alcohol, both as a source and symbol of inequality and class conflict. In addition, changing relationships, and tensions, between men and women were themes that cut across most of the ethnographies we reviewed. Women's interests often lose ground as men's drinking increases in the context of development. Commercialization of production may also mean that women lose control over what was traditionally a home-produced supply. Many of the developing societies we studied shared long-standing traditions of home production by women-traditions that helped balance a gendered distribution of wealth. As countries entered the global economy, local markets were often colonized and women's independent source of wealth dried up. The declining wealth and independence of women often took place within a context in which the status of men was under threat as well. In studies of Fiji, Chuuk, Zambia and Papua New Guinea, development left local men dislocated from their former political and economic statuses, producing role strain. Among other things, increased drinking and alcohol-related violence among men seemed a by-product of their growing sense of demoralization and loss of control.

Historically, alcohol has provided many colonial governments with a means to control and dominate indigenous populations, as well as a way to extract more in the way of labor and taxes from local populations. It is only natural, then, that foreign sources of alcohol have become symbolically tied to struggles against foreign incursion in many parts of the developing world. Cases of alcohol boycotts and spontaneous prohibition movements "from below" underscore the fact that, as tribal and village societies are incorporated into the globalized cash economy, they often lose the ability to regulate themselves. These popular movements voice the need for action at national and sub-national levels to protect public health and order interests, to provide a shield from the most deleterious aspects of the globalized commercial promotion of alcohol, and to support community self-regulation.

\section{Implications}

In international health, ethnographic research is often confined to the roles of hypothesis generation and measuring cross-cultural applicability-to produce findings only later validated through quantitative means. We tend to view this body of work as a series of rich, but isolated, snapshots of particular people, in a particular place and time. However, the common threads observed across the developing societies in this review may encourage us to think about the ethnographic record as its own coherent body of scientific evidence-as well as a declining resource as more lowand middle-income countries cross the epidemiological transition to become part of the developed world.

Reframing the ethnographic record as a coherent body of research on a par with quantitative studies opens up possibilities for more systematic cross-cultural secondary analyses to inform policymaking and practices in international health. We can expect that in many other areas of public health, besides alcohol, there already exist reasonably large, well-developed ethnographic records to be mined. More systematic studies of these data sources could suggest ways to better understand the dynamics of developing countries. Even more important, they could suggest better ways to intervene on behalf of producing health equality within and between countries. After all, the field of public health has its own dual nature: it is part science and part politics. The ethnographic record is unique in its capacity to speak to both sides of the duality-both as a scientific investigation, and as a rich fund of symbols and imagery around which to build political coalitions and motivate change.

\section{References}

Abeyansinghe, R. (2002). Illicit alcohol: Drinking culture in Colombo-A study of alcohol consumption among the urban poor in a South Asian capital. Colombo, Sri Lanka: Vijitha Yapa

Publications. 
Australian Indigenous Doctors' Association \& Centre for Health Equity Training, Research and Evaluation. (2010). Health impact assessment of the Northern Territory emergency response. Canberra, Australia: Australian Indigenous Doctors' Association. Retrieved from http://www.aida.org.au/ viewpublications.aspx?id=3

Beckman, V. (I988). Alcohol: Another trap for Africa. Örebro, Sweden: Libris.

Benegal, V., Nayak, M., Murthy, P., Chandra, P., \& Gururaj, G. (2005). Women and alcohol use in India. In I. S. Obot \& R. Room (Eds.) Alcohol, gender and drinking problems: Perspectives from low and middle income countries (pp. 89-123). Geneva, Switzerland: Department of Mental Health and Substance Abuse, World Health Organization.

Blas, E., \& Sivasankara Kurup, A., (Eds.) (2010). Equity, social determinants and public health programmes. Geneva, Switzerland: World Health Organization. Retrieved from http://www.who.int/social_determinants/en/

Braveman, P., \& Gruskin, S. (2003). Defining equity in health. Journal of Epidemiology and Community Health, 57, 254-258.

Butler, B. Y. (2006). Holy intoxication to drunken dissipation: Alcohol among Quichua speakers in Otavalo, Ecuador. Albuquerque, U.S.A.: University of New Mexico Press.

Colson, E., \& Scudder, T. (I988). For prayer and profit: The ritual, economic, and social importance of beer in Gwembe District, Zambia, 1950-1982. Stanford, U.S.A.: Stanford University Press.

Dorschner, J. P. (1983). Alcohol consumption in a village in North India (Vol. I). Ann Arbor, U.S.A.: UMI Research Press.

Eber, C. (I995). Women and alcohol in a highland Maya town: Water of hope, water of sorrow. Austin, U.S.A.: University of Texas Press.

Eber, C. (200I). “Take my water": Liberation through prohibition in San Pedro Chenalho, Chiapas, Mexico. Social Science \& Medicine, 53, 25I-262.

Ezzati, M., Lopez, A .D., Rodgers, A., Vander Horn, S., Murray, C. J. L., \& Comparative Risk Assessment Collaborating Group. (2002). Selected major risk factors and global and regional burden of disease. Lancet, 360, I347I360.

Fahey, D. M., \& Manian, P. (2005). Poverty and purification: The politics of Gandhi's campaign for prohibition. The Historian, 67, 489-506.
Grossman, L. (1982). Beer drinking and subsistence production in a highland village. In $\mathrm{M}$. Marshall (Ed.), Through a glass darkly: Beer and modernization in Papua New Guinea (pp. 5972). Boroko, Papua New Guinea: Institute for Applied Social and Economic Research.

Jarratt, P., \& Zwar, D. (I989). Dreamtime or genocide? The Bulletin (Sydney, Australia), I November, 44-48.

Jernigan, D. (I997). Country profile on alcohol in Zimbabwe. In L. Riley \& M. Marshall (Eds.), Alcohol and public health in eight developing countries (pp. I57-I75). Geneva, Switzerland: Substance Abuse Department, World Health Organization.

Kawachi, I., Kennedy, B. P., \& Wilkinson, R. G. (Eds.). (I999). The society and population health reader: Income inequality and health (Vol. I). New York, U.S.A.: New Press.

La Hausse, P. B. (1988). Brewers, beerhalls and boycotts: A history of liquor in South Africa. Johannesburg, South Africa: Ravan Press.

Macintyre, M. (1999). Social and economic impact study, Lihir 1998. Melbourne, Australia: Charlotte Allen and Associates.

Macintyre, M. (2005, November). "Mi laikim spak tasol" [I just want to get drunk]: Alcohol consumption patterns in Lihir 1995-2005. Paper presented at the meeting of Dangerous Consumptions III, University of Melbourne.

Mäkelä, K., \& Viikari, M. (I977). Notes on alcohol and the state. Acta Sociologica, 20, I55-179.

Marshall, M., \& Marshall, L. B. (I975). Opening Pandora's bottle: Reconstructing Micronesians' early contacts with alcoholic beverages. Journal of the Polynesian Society, 84, 44I-465.

Marshall, M., \& Marshall, L. B. (1976). Holy and unholy spirits. Journal of Pacific History, 11, I35I66.

Marshall, M., \& Marshall, L. B. (I990). Silent voices speak: Women and prohibition in Truk. Belmont, U.S.A.: Wadsworth.

Maula, J. (I997). Small-scale production of food and traditional alcoholic beverages in Benin and Tanzania: Implications for the promotion of female entrepreneurship. Helsinki, Finland: Finnish Foundation for Alcohol Studies.

McKnight, D. (2002). From hunting to drinking: The devastating effects of alcohol on an Australian Aboriginal community. New York, U.S.A.: Routledge.

Narayan, K. M. V., Ali, M. K., \& Koplan, J. P. (20I0). Global noncommunicable diseases- 
Where worlds meet. New England Journal of Medicine, 363, I996-I198.

Pine, A. (2008). Working hard, drinking hard: On violence and survival in Honduras. Berkeley, U.S.A.: University of California Press.

Room, R. (ig84). Alcohol and ethnography: A case of problem deflation? Current Anthropology, 25, I69-I9I.

Room, R. (2008). "Justly anxious respecting the moral and material consequences.” The proliferation of international control regimes for psychoactive substances. Social History of Alcohol and Drugs, 22, 6-2I.

Room, R., Babor, T., \& Rehm, J. (2005). Alcohol and public health. Lancet, 365, 519-530.

Room, R., Mäkelä, P., Schmidt, L., \& Rehm, J. (2006). Alcohol, health disparities and development. Expert committee meeting. Geneva, Switzerland: World Health Organization.

Room, R., Rehm, J., \& Parry, C. (2OII). Alcohol and NCDs: Time for a serious international public health effort. Addiction, 106, I547-I548.

Room, R., Rehm, J., Trotter, R. T., Paglia, A. \& Üstün, T. B. (200I). Cross-cultural views on stigma, valuation, parity and societal attitudes towards disability. In T. B. Üstün, S. Chatterji, J. Rehm, S. Saxena, J. E. Bickenbach, R. T. Trotter, \& R. Room (Eds). Disability and culture: Universalism and diversity (pp. 247-29I). Seattle, U.S.A.: Hofgrebe \& Huber.

Schmidt, L., Mäkelä, P., Rehm, J., \& Room, R. (2010). Alcohol: Equity and social determinants. In E. Blas \& A. Sivasankara Kurup (Eds.), Equity, social determinants and public health programmes (pp. II-29). Geneva, Switzerland: World Health Organization. Retrieved from http://www.who.int/social_determinants/en/

Silberschmidt, M. (I990). The interaction between changing male and female roles and alcohol problems in rural Kenya: Observations from a field study in Kisii District. In J. Maula, M. Lindblad, \& C. Tigerstedt (Eds.), Alcohol in developing countries (pp. I34-I50). (NAD Publication I8). Helsinki, Finland: Nordic Council for Alcohol and Drug Research.

Thimmaiah, G., \& Sharma, J. V. M. (1978). Socioeconomic impact of drinking in Karnataka. Calcutta, India: Institute of Social Studies.

Toren, C. (I994). Drinker as chief or rebel: Kava and alcohol in Fiji. In M. McDonald (Ed.), Gender, drink and drugs (pp. I53-I73). Oxford, U.K.: Berg.
United Nations General Assembly (20II). Political declaration of the high-level meeting of the Assembly on the Prevention and Control of Noncommunicable Diseases. 66th Session, Agenda Item 117. New York, U.S.A.: United Nations.

Weinstein, L. (I976). Alcoholism as a political problem in Chile. Mental Health a Society, 3 , 72-76.

Wright, A. (I997). Grog war. Broome, Australia: Magabala Books Aboriginal Corporation. 